Gates, T. S., K.S. Whitley, R.W. Grenoble, T. Bandorawalla, "Thermal/Mechanical Durability of Polymer Matrix Composites in Cryogenic Environments", AIAA-2003-7408, 44th Annual AIAA/ASME/ASCE/AHS/ASC Structures, Structural Dynamics, and Materials Conference, Norfolk, VA, April 7-10, 2003.

\title{
Thermal/Mechanical Durability of Polymer-Matrix Composites in Cryogenic Environments ${ }^{1}$
}

\author{
Thomas S. Gates*, Karen S. Whitley ${ }^{\dagger}$, Ray W. Grenoble ${ }^{\star}$, Tozer Bandorawalla ${ }^{\S}$ \\ NASA Langley Research Center \\ Hampton, VA 23681
}

\begin{abstract}
$\underline{\text { Abstract }}$
In order to increase the reliability of the next generation of space transportation systems, the mechanical behavior of polymeric-matrix composite (PMC) materials at cryogenic temperatures must be investigated. This paper presents experimental data on the residual mechanical properties of a carbon fiber polymeric composite, IM7/PETI-5 as a function of temperature and aging. Tension modulus and strength were measured at room temperature, $-196^{\circ} \mathrm{C}$, and $269^{\circ} \mathrm{C}$ on five different specimens ply lay-ups. Specimens were preconditioned with one set of coupons being isothermally aged for 576 hours at $-184^{\circ} \mathrm{C}$, in an unloaded state. Another set of corresponding coupons were mounted in constant strain fixtures such that a constant uniaxial strain was applied to the specimens for 576 hours at $-184^{\circ} \mathrm{C}$. A third set was mechanically cycled in tension at $-184^{\circ} \mathrm{C}$. The measured properties indicated that temperature, aging, and loading mode can all have significant influence on performance. Moreover, this influence is a strong function of laminate stacking sequence. Thermal-stress calculations based on lamination theory predicted that the transverse tensile ply stresses could be quite high for cryogenic test temperatures. Microscopic examination of the surface morphology showed evidence of degradation along the exposed edges of the material because of aging at cryogenic temperatures.
\end{abstract}

\footnotetext{
*Senior Materials Research Engineer, Mechanics and Durability Branch. Associate Fellow, AIAA.

${ }^{\dagger}$ Aerospace Engineer, Mechanics and Durability Branch.

${ }^{\ddagger}$ Graduate Co-op, Mechanics and Durability Branch.

${ }^{\S}$ Post-doctoral associate, Old Dominion University.

${ }^{1}$ Copyright 2003 by the American Institute of Aeronautics and Astronautics, Inc. No copyright is asserted in the United States under Title 17, U.S. Code. The U.S. Government has a royalty-free license to exercise all rights under the copyright claimed herein for Government Purposes. All other rights are reserved by the copyright owner.
}

\section{Introduction}

The National Aeronautics and Space Administration (NASA) Space Shuttle is the only launch vehicle in service today with reusable components. To address the issues of an aging Space Shuttle fleet, and to advance key technologies associated with increased performance, NASA has initiated the Space Launch Initiative (SLI) program. One of the key performance advances identified for next-generation reusable launch vehicles (RLV's) is the reduction in structural weight through the use of advanced materials and manufacturing methods. This reduction in structural weight must be tempered against the safety and reliability criteria associated with damage tolerance, and lifetime durability.

It is envisioned that the next-generation RLV will have integral liquid-hydrogen $\left(\mathrm{LH}_{2}\right)$ and liquid-oxygen (LOX) cryogenic fuel tanks that not only function to contain the fuel but must also perform as load-carrying structure during launch and flight operations. Presently, is appears that replacement of traditional metallic cryogenic fuel tanks with polymeric matrix composite (PMC) tanks may lead to significant weight reduction and hence increased load-carrying capabilities.

Despite the lack of long-term flight data, there is some history of design and testing of PMC cryogenic tanks that includes the National Aerospace Plane

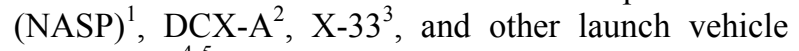
applications ${ }^{4},{ }^{5}$. These programs have considered several tank wall design concepts including externally stiffened shells of PMC material or thin-walled sandwich shells constructed with a lightweight core and PMC facesheets.

Regardless of the design, the next generation of PMC-based tanks will be required to safely carry pressure and flight loads and to operate over temperatures that may range from $-250^{\circ} \mathrm{C}$ to $+120^{\circ} \mathrm{C}$. From a durability perspective, the primary performance criteria of the PMC material is to retain mechanical properties within allowable limits over the life-time of the tank while minimizing loss of cryogenic fuel because of permeation or leakage through the tank wall.

Other than space launch vehicle applications, there have been very few uses of PMC's as structural 
materials in cryogenic environments and consequently the available literature provides limited experimental data on the mechanical properties of polymers or PMC's operating at cryogenic temperatures.

Related to durability, long-term fatigue tests were performed by Pannkoke ${ }^{6}$ on unidirectional thermoplastic composites at $-196^{\circ} \mathrm{C}$. The fatigue strength was found to be only $60 \%$ of the static strength at $10^{6}$ cycles. In this work, it was recognized that large thermal stresses degraded the fatigue performance. In a series of articles by Alhborn ${ }^{7,8}$, static and cyclic thermal/mechanical tests were performed on unidirectional and cross-ply thermoplastic composites. He conducted isothermal tests at $23^{\circ} \mathrm{C},-196^{\circ} \mathrm{C}$, and $-269^{\circ} \mathrm{C}$ and cyclic thermal tests between $-196^{\circ} \mathrm{C}$ and $23^{\circ} \mathrm{C}$. Strength, damage, and fatigue life were measured for all test conditions. It was found that the effects of temperature on static strength were largely related to the matrix-dominated properties, shear and transverse tension. Increases in matrixdominated strength as the temperature is decreased could be offset by the development of thermal-stressinduced cracks. As in previous studies, the fatigue life was reduced as the test temperature was decreased. Matrix dominated properties are a function of the polymer material properties. For amorphous and crystalline polymeric materials, Perepechko ${ }^{9}$ provides details on a number of non-mechanical properties including thermal expansion, thermal conductivity, as well as viscoelastic or dynamical mechanical properties. From these studies, it is clear that many of the cryogenic polymer properties are not linear with respect to temperature.

Schutz $^{10}$ has provided a compilation of test data for several PMC material systems. He showed that, in general, static properties such as tensile modulus, tensile strength, and compressive strength all increased as the test temperature was decreased from $23^{\circ} \mathrm{C}$ to $-269^{\circ} \mathrm{C}$. Once again, it was found that thermal stresses had a large influence on behavior and that the sensitivity of matrix-dominated properties to temperature can be used to help explain the stress-strain response of laminated composites.

Of these matrix-dominated properties, transverse ply strength may play a critical role in the development and growth of residual-stress-induced matrix cracks. The range of thermal and mechanical loading over which steady-state matrix cracking may occur was investigated recently by Schoeppner ${ }^{11}$. Additional studies related to matrix crack development in PMC's because of cryogenic temperature exposure is found in ref. ${ }^{12}$ and ref..$^{13}$.

The lack of long-term thermal/mechanical performance data on an advanced composite, such as IM7/PETI-5, subjected to a cryogenic environment, is clearly evident. Therefore, the objectives of the present paper are to assess the thermal/mechanical durability of
IM7/PETI-5 at cryogenic temperatures, document the test methods, and provide insights into the effects of temperature and aging on mechanical performance. The selected test conditions represent a range of exposure times, loads and temperatures similar to those experienced during the lifetime of a cryogenic, hydrogen fuel tank. Results are given for tension and compression-loaded coupons subjected to temperatures that ranged from room temperature to $-269^{\circ} \mathrm{C}$. Fundamental, lamina-level material properties were measured, analyzed, and correlated against test environment. Residual stiffness and strength, and damage will be given as a function of both cryogenic test temperatures and pre-test cryogenic aging conditions. Results from thermal stress analysis are presented to illustrate the effect of temperature and aging on the stress state in typical laminates.

It is recognized that a broad spectrum of factors influence the properties of PMC's including material selection, composite fabrication and handling, aging or preconditioning, specimen preparation, laminate ply lay-up, test procedures, etc. This study focuses on test temperature, preconditioning methods (load, temperature and time), and laminate configuration as the primary test variables. It is expected that the results of this study will be important in the development of future material qualification methods and design verification testing.

\section{Material System}

The PMC material used in this study, IM7/PETI5, consisted of a continuous, high-strength, intermediate-modulus, carbon fiber in a thermoplastic polyimide matrix. All test materials were laminated composites, fabricated at the NASA Langley Research Center. These composite panels consisted of unidirectional and angle-ply laminates, $\left([0]_{12},[90]_{12}\right.$, $\left.[ \pm 25]_{3 \mathrm{~S}}, \quad[ \pm 45]_{3 \mathrm{~S}}\right)$, and a 13-ply quasi-orthotropic laminate $\left(\left[45 / 90_{3} /-45 / \overline{0}_{3}\right]_{\mathrm{S}}\right)$. The bar notation over the 0 indicates that the $0_{3}$ ply group is not symmetric. Fig. 1 provides a schematic illustrating the coordinate system for the fiber orientations relative to the specimen dimensions.

These lay-ups were chosen to provide basic laminalevel material constants and in the case of the $\left[45 / 90_{3} /-45 / \overline{0}_{3}\right]_{\mathrm{S}}$ laminate, to be representative of a composite wall in a typical cryogenic propellant tank. For a cryogenic tank, the orientation of the $0^{\circ}$ ply in the $\left[45 / 90_{3} /-45 / \overline{0}_{3}\right]_{\mathrm{S}}$ laminate would be in the longitudinal axis direction of the tank.

All composite panels were fabricated by hand lay-up. The bagging and cure processes employed were consistent with standard practices. The cure cycle consisted of a $60 \pm 10$ minute hold at $260^{\circ} \mathrm{C}$ under full vacuum, followed by pressurization of the autoclave to $1480 \pm 35 \mathrm{kPa}$ at $170 \pm 14 \mathrm{kPa} /$ minute during ramp to 
$370^{\circ} \mathrm{C}$ for $60 \pm 10$ minutes. Through-transmission, ultrasonic inspection indicated that there were no significant internal anomalies in any of the panels. The glass transition temperature $\left(\mathrm{T}_{\mathrm{g}}\right)$ of the as-received composite material was $267^{\circ} \mathrm{C}$ as measured by the peak in the Tan $\delta$ curve of tests run in a dynamic mechanical analysis (DMA) test.

\section{Material Characterization}

The material characterization test plan consisted of two phases that are described in this section. The first phase was material preconditioning and addressed material aging. In this phase, the material was subjected to long-term exposure at cryogenic temperature in an unloaded, statically loaded, or cyclic loaded (tension only) state. The second phase was static residual property characterization (tension and compression) of aged and not aged specimens at three temperatures $\left(23^{\circ}\right.$, $-196^{\circ}$, and $-269^{\circ} \mathrm{C}$ ). This phase provided fundamental material properties and an understanding of material behavior as a function of prior aging conditions and test temperatures. The complete test matrix, including the phase one aging conditions and the phase two residual property tests are shown in table 1 .

All tests were conducted on coupon-type test specimens that were cut from the larger panels prior to aging. Three replicates of each condition were tested for generating the data. A schematic of the tension test coupon and coordinate axis is presented in Fig. 1.

The cryogenic tension coupons were $254 \mathrm{~mm}$ long and were mounted in the test fixture to provide a 127 $\mathrm{mm}$ test-section. The room temperature tensile coupons were $152.4 \mathrm{~mm}$ long with a $76.2 \mathrm{~mm}$ test section.

The residual tension tests were conducted according to standards SACMA SRM4-88 and ASTM D3039-76. The tensile modulus was calculated by using ASTM D3039-76 and a linear regression least squares curve fit of the stress-strain data in the linear region of the data. The linear region of the stress-strain curve was most commonly defined as being between $1000 \mu \varepsilon$ and $3000 \mu \varepsilon$ for all test conditions and specimen ply lay-ups.

A schematic of the compression coupon is presented in Fig. 2. The gauged coupon is placed in the center cut-out section of the compression test fixture, as shown in Fig. 3(a). The fixture is assembled as shown in the side view of Fig. 3(b). The coupon in the fixture is end-loaded under compression. The compression tests were performed by using the SACMA recommended method SRM 1-88 and the ASTM D695 references as guides. The compressive strength and modulus were calculated according to the method described in ASTM D695, by calculating the slope of the tangent to the initial linear portion of the stressstrain curve. In most cases, the linear region of the stress-strain curve from the compression test was defined as being between $1000 \mu \varepsilon$ and $2000 \mu \varepsilon$ for all test conditions and specimen ply lay-ups.

\section{Test phase one - Material aging}

Three types of material aging or preconditioning were used in the test program. The first condition was isothermal exposure of test coupons for 576 hours at $184^{\circ} \mathrm{C}$, without mechanical load. The test equipment was a cryo-freezer that used gaseous nitrogen as the cryogen. The second aging condition was isothermal at $-130^{\circ} \mathrm{C}$, with cyclic mechanical load. The cyclic load was applied in a servo-hydraulic test machine at a frequency of 2.3 cycles per minute, at an R-ratio of 0.10 . The maximum strain was approximately $0.5 \%$ and total test duration was approximately 7 hours. The third aging condition was isothermal exposure of test coupons for 576 hours at $-184^{\circ} \mathrm{C}$, with a constant strain applied using a mechanical loading fixture and the aforementioned cryo-freezer.

The constant-strain test fixture, shown in Fig. 4, was constructed of Invar material (CTE $=1.4 \mu$ $\mathrm{mm} / \mathrm{mm}-{ }^{\circ} \mathrm{C}$ ) and could accommodate two rectangular specimens. Each specimen was individually preloaded to the desired strain level by compressing a series of spring-type washers that react against the frame and put the specimen into tension. Applying torque to the loading nut tightened the washers and the strain in the specimen was monitored with a longitudinal extensometer mounted on the specimen.

The preload strain level was approximately $0.3 \%$ to $0.4 \%$ and was selected to be approximately $50 \%$ of the room temperature failure strain. The high stiffness of the fixture relative to the test specimen and the low CTE of the Invar material ensured a constant strain condition over the entire aging period.

For the baseline or not aged condition, coupons were cut from the same panels as the aged coupons and tested for residual properties by using the same procedures as the aged coupons.

\section{Test phase two - Residual properties}

In phase two of the test program, residual strength and stiffness were measured for both the aged and baseline coupons. All residual property tests were performed on a servo-hydraulic test machine by using a displacement rate of $1.27 \mathrm{~mm} / \mathrm{min}$. The isothermal cryogenic test conditions at $-196^{\circ} \mathrm{C}$ and $-269^{\circ} \mathrm{C}$ were achieved by immersing the test specimen and load introduction apparatus into liquid nitrogen or liquid helium respectively. In order to reach thermal equilibrium, the specimen stayed immersed in a constant level of the cryogen for at least 15 minutes prior to mechanical loading.

Stress in the test specimens was approximated by using load, as measured by the test machine load cell, divided by the original cross section of the specimen. Strain in the test specimen was measured by using combinations of cryogenic-rated axial extensometers 
and bonded electrical-resistance strain gages. Temperature compensation was achieved by zeroing the extensometer and/or gages after the specimen reached thermal equilibrium. Placement of these sensors on the specimen is shown in Figs. 1 and 2.

Prior to aging exposure, representative samples were polished along one edge. Optical microscopy was used to investigate for damage (microcracks, delamination), and photomicrographs were taken to establish the baseline condition. After aging exposure, but prior to the destructive residual tests, visual examination of all lay-ups was again performed to determine if the exposure conditions generated any microcracks, damage, or change in surface morphology.

\section{Results and Discussion}

The residual mechanical properties will be presented as a function of both temperature and aging. Specifically, the residual elastic modulus and strength results are presented for laminates with $[0]_{12},[ \pm 25]_{3 \mathrm{~S}}$, $\left[45 / 90_{3} /-45 / \overline{0}_{3}\right]_{\mathrm{S}},[90]_{12}$, and $[ \pm 45]_{3 \mathrm{~S}}$, ply stacking sequence. Table 2 and table 3 contain the tensile and compressive elastic moduli, respectively, at the three different test temperatures, for each lay-up and for each aging condition. Each value in the tables represents the average of three replicates along with the standard deviation.

The lamina in-plane stiffness values $E_{1}$ and $E_{2}$, were calculated directly from stress-strain behavior of the $[0]_{12}$ and $[90]_{12}$ unidirectional laminates, respectively. The laminate stiffness value $E_{x}$ of the $[ \pm 25]_{3 \mathrm{~S}}$ and $\left[45 / 90_{3} /-45 / \overline{0}_{3}\right]_{S}$, laminates was calculated from the laminate stress-strain behavior. Lamina in-plane shear modulus $G_{12}$ was calculated indirectly from the stressstrain behavior of the $[ \pm 45]_{3 \mathrm{~S}}$ laminates by using the Eq.,

$$
G_{12}=\frac{E_{x}}{2\left(1+v_{x y}\right)}
$$

where $v_{\mathrm{xy}}$ is the laminate Poisson's ratio and $E_{x}$ is the laminate longitudinal modulus.

Measured values of laminate tensile and compressive strength are listed in table 4 and table 5, respectively, along with the associated standard deviation. Failure was defined as the point of complete loss of load carrying capability during the test. Because of the nonlinear nature of the stress-strain behavior in $[ \pm 45]_{3 \mathrm{~S}}$ laminates, their tensile strength was defined as the initial point of deviation from the nearly horizontal portion of the stress-strain curve.

\section{Effect of Temperature on Modulus and Strength}

The effects of temperature on tensile modulus and strength were found by examining the results from specimens subjected to the not-aged test condition. The fiber-dominated $[0]_{12}$ laminate experienced a decrease in both the modulus and strength at cryogenic temperatures, with up to a $35 \%$ decrease in strength for the $-196^{\circ} \mathrm{C}$ case. Conversely, the shear modulus and longitudinal strength of the $[ \pm 45]_{3 \mathrm{~S}}$ matrix-dominated laminate increased as the temperature decreased. In particular, the shear modulus increased by as much as $35 \%$ and the strength by as much as $50 \%$ when tested at $-269^{\circ} \mathrm{C}$. The transverse modulus $\left(\mathrm{E}_{2}\right)$ showed a slight decline at cryogenic temperatures while the transverse strength dropped by approximately $70 \%$ when the temperature was reduced to $-269^{\circ} \mathrm{C}$. The $[ \pm 25]_{3 \mathrm{~S}}$ laminate modulus or strength showed little sensitivity to exposure to cryogenic temperature.

The tensile modulus and strength of the not aged $\left[45 / 90_{3} /-45 / \overline{0}_{3}\right]_{\mathrm{S}}$ decreased by nearly $20 \%$ at $-196^{\circ} \mathrm{C}$, with some reduction in this decline as the temperature was lowered to $-269^{\circ} \mathrm{C}$. To illustrate this behavior, the not aged modulus, strength and failure strain of the $\left[45 / 90_{3} /-45 / \overline{0}_{3}\right]_{\mathrm{S}}$ laminate are plotted in Fig. 5. The data were normalized against the room temperature case to clearly depict the effect of temperature.

The compressive modulus and strength increased for all laminates exposed to cryogenic temperatures. In most cases, the highest modulus and strength occurred at the lowest test temperature $\left(-269^{\circ} \mathrm{C}\right)$. Of all the laminates tested, the $[90]_{12}$ experienced the greatest increase $(67 \%)$ in strength, while the $[ \pm 45]_{3 \mathrm{~s}}$ experienced the greatest increase $(57 \%)$ in modulus due to cryogenic temperatures.

\section{Effect of Aging on Modulus and Strength}

To determine the effects of aging, the not-aged condition was compared to the aged without load, the aged with load, and the cycled conditions. In general, aging had very little effect on the tensile modulus of the $[0]_{12}$ fiber-dominated laminate. Aging did cause a slight increase in tensile strength for the $[0]_{12}$ laminate with the most significant change occurring when tested at $-269^{\circ} \mathrm{C}$, after aging with load. Aging did not significantly affect the shear modulus or longitudinal strength of the $[ \pm 45]_{3 \mathrm{~S}}$ matrix-dominated laminate.

For the $\left[45 / 90_{3} /-45 / \overline{0}_{3}\right]_{\mathrm{S}}$ laminate, aging increased the modulus. The largest increase (18\%) occurred for the aged-with-load, tested at $-269^{\circ} \mathrm{C}$ condition. Aging also increased the strength of the $\left[45 / 90_{3} /-45 / \overline{0}_{3}\right]_{S}$ laminate, with the most significant increase occurring at the aged-with-load condition where strength increased relative to the baseline by $21 \%$ at $-196^{\circ} \mathrm{C}$ and $11 \%$ at $-269^{\circ} \mathrm{C}$. In general, aging decreased the modulus of the $[ \pm 25]_{3 \mathrm{~S}}$ laminate and had little effect on the laminate strength. From the limited data for the $[90]_{12}$ laminate, it appears that aging had little effect on transverse modulus or strength. 
As an illustrative example of the effects of aging, residual tension strength of the $\left[45 / 90_{3} /-45 / \overline{0}_{3}\right]_{\mathrm{s}}$ laminate at all three temperatures, has been normalized against the not-aged, room-temperature condition and plotted in Fig. 6.

As expected, the standard deviation in strength measurements was more significant than the standard deviation associated with modulus. In part, this deviation is because of strength being a point or single value whereas modulus is an overall or effective property based on the trend in a stress-strain curve. Strength in laminated composites is also more sensitive to the processing, handling, or test parameter variability.

The compressive modulus and strength of the $[0]_{12}$ laminate were not greatly influenced by aging. The $[ \pm 45]_{3 \mathrm{~S}}$ matrix dominated laminate showed a decrease in modulus and strength because of aging in most cases, and the modulus generally decreased more than the strength. The compressive modulus of the $\left[45 / 90_{3} /-\right.$ $\left.45 / \overline{0}_{3}\right]_{\mathrm{S}}$ laminate tended to decrease after aging. The compressive strength of the $\left[45 / 90_{3} /-45 / \overline{0}_{3}\right]_{\mathrm{s}}$ laminate increased because of aging. The greatest increase $(88 \%)$ occurred at $-269^{\circ} \mathrm{C}$ after aging with load, however the standard deviation associated with those strength values was quite high. The room-temperature modulus and strength of the $[ \pm 25]_{3 \mathrm{~S}}$ laminate were unaffected by aging, however at $-196^{\circ} \mathrm{C}$ both modulus and strength increased because of aging. The $[90]_{12}$ laminate was not significantly affected by aging.

\section{Surface Morphology}

Optical examination of surface morphology was intended to provide data on the initiation and growth of any damage that occurred during specimen aging. Very few microcracks or similar damage was observed before or after aging in any of the lay-ups. However, the surface morphology showed that some definite degradation had occurred along the exposed edges after aging without load and it appeared that further surface degradation occurred after aging with load. This degradation was present in all lay-ups and can be described as pitting in the matrix regions.

\section{Thermal Stress Analysis}

As evidenced by many of the previous cited studies, in the absence of mechanical loading, application of thermal loading may be sufficient to induce thermal stresses that lead to degradation in laminate performance. For thermal loading, stresses are induced at the ply level by material expansion or contraction and the constraining effects of adjacent plies that prevent free relative expansion or contraction. This residual stress in any ply can be calculated by using classical laminated plate theory ${ }^{14}$. In general, for a laminated, unidirectional plate under plane stress, the constitutive relationship includes the combination of the mechanical and thermal strains, that is,

$$
\left\{\begin{array}{l}
\sigma_{11} \\
\sigma_{22} \\
\sigma_{12}
\end{array}\right\}=[Q]\left(\left\{\begin{array}{l}
\varepsilon_{11} \\
\varepsilon_{22} \\
\gamma_{12}
\end{array}\right\}-\left\{\begin{array}{l}
\varepsilon_{11} \\
\varepsilon_{22} \\
\gamma_{12}
\end{array}\right\}^{T}\right)
$$

where $\sigma$ is the stress, $Q$ is the material stiffness matrix, and the mechanical strain is the difference between the total and the thermal strain $\varepsilon^{T}$. For a single lamina or ply, this thermal strain is calculated by using

$$
\left\{\begin{array}{c}
\varepsilon_{11}^{T} \\
T \\
\varepsilon_{22}^{T} \\
\gamma_{12}^{T}
\end{array}\right\}=\left\{\begin{array}{c}
\alpha_{1} \\
\alpha_{2} \\
0
\end{array}\right\} \Delta T
$$

where $\varepsilon$ is the normal strain, $\gamma$ is the shear strain, $\alpha$ is the coefficient of thermal expansion (CTE), and $\Delta T$ is the temperature differential between the test condition and the stress free condition at cure. Subscripts in Eqs. 2 and 3 refer to the standard notation (1=fiber direction, $2=$ transverse direction).

Clearly, from Eq. (3) it is apparent that for large values of $\Delta T$, a condition at cryogenic temperatures, the magnitude of the thermally induced strains is highly dependent on the material CTE values. In particular, nonlinear behavior of the CTE with respect to temperature, as illustrated in table 6 , may result in thermal residual stresses that also vary in a nonlinear manner with respect to temperature. To illustrate this effect, material properties given in tables 2-5 and CTE values from table 6 were used as inputs to classical laminated-plate theory to predict the maximum transverse ply stress as a function of laminate stacking sequence, test temperature, and laminate preconditioning.

The prediction of maximum transverse ply stress $\left(\sigma_{22}\right)$ is of primary interest because it is this stress that is considered to directly contribute to the initiation and growth of transverse matrix cracks and subsequent loss of strength and stiffness. It should be noted that the CTE values were taken as the not-aged values for all conditions and the stress-free temperature was assumed to be the glass transition temperature of IM7/PETI-5.

Examples from the results of these calculations are given in Figs. 7-9. With respect to temperature, Fig. 7 indicates that the trend for the not-aged condition is for transverse stress to increase with a decrease in temperature. To simulate the combined influence of temperature and mechanical load, a stress corresponding to $( \pm 0.4 \%)$ strain was included to represent tension or compression loading. Fig. 8 shows the predicted maximum transverse ply stress at $-269^{\circ} \mathrm{C}$ 
for a combined thermal/mechanical load using the baseline properties. The additive or subtractive effects of the combined thermal and mechanical loads is evident for all three layups, with the matrix-dominated $[ \pm 60]_{3 \mathrm{~s}}$ layup being influenced the most by the change from tension to compression loading.

With respect to aging, Fig. 9 shows that at the $269^{\circ} \mathrm{C}$ test temperature, the aged with load condition resulted in the largest transverse ply stress when compared to the baseline and aged-without-load conditions.

\section{Summary and Conclusions}

Five different laminate configurations of IM7/PETI5 that were evaluated for tensile and compressive strength and stiffness at room temperature and two cryogenic test temperatures have been examined. The effects of laminate configuration, test temperature, and preconditioning or aging were investigated. The specimens were examined for evidence of damage or microcracking before and after aging.

Results obtained for the basic lamina properties such as strength and stiffness in the longitudinal, transverse, and shear directions indicate that cryogenic temperatures can significantly influence performance. For tension loading, longitudinal and transverse stiffness and strength decreased as the test temperature decreased. Conversely, the tensile shear modulus and strength increased as the temperature decreased. Also for tension loading, the $\left[45 / 90_{3} /-45 / \overline{0}_{3}\right]_{\mathrm{S}}$ and $[ \pm 25]_{3 \mathrm{~S}}$ laminates were less influenced by temperature than the other laminates considered. However, the $\left[45 / 90_{3} /-\right.$ $\left.45 / \overline{0}_{3}\right]_{\mathrm{S}}$ laminate was more sensitive to cryogenic temperatures than the $[ \pm 25]_{3 \mathrm{~S}}$ laminate. For compression loading, cryogenic temperatures produced an increase in both the modulus and strength of all the laminates. The greatest increase in compressive strength occurred in the $[90]_{12}$ laminates and the greatest increase in modulus occurred in the $[ \pm 45]_{3 \mathrm{~s}}$ laminates.

Aging the material under isothermal, cryogenic temperature caused changes in the strength and stiffness as compared to the not aged or as-received material. The results due to aging were mixed illustrating the dependence on laminate stacking sequence and loading conditions. Residual-stress calculations, based on lamination theory, showed that the transverse tensile ply stresses can be quite high for cryogenic test temperatures. Moreover, the angle-ply and typical design laminates were predicted to have the highest residual stresses in the transverse direction. These transverse residual stresses are generally expected to degrade strength and stiffness by contributing to the initiation and growth of transverse microcracks in a ply.

Some major findings of this study include the following. First, response trends in stiffness and strength variations with changes in temperature are not always smooth, indicating that tests should be run at all temperature levels of interest. Second, loading condition and directions have a significant influence on both stiffness and strength. Third, aging or long-term exposure to cryogenic temperature while under load can significantly alter the as-received mechanical properties, implying that design criteria should take into account thermal/mechanical exposure over the life-time of the structure.

\section{References}

1. Robinson, M.J., Composite Cryogenic Propellant Tank Development in 35th Structures, Structural Dynamics, and Materials Conference, April, 1994, Hilton Head, South Carolina, AIAA-94-1375-CP, p.544-551.

2. Robinson, M.J., Composite Structures on the DCXA Reusable Launch Vehicle in 28th International SAMPE, November, 1996, Seattle, Washington.

3. NASA, Final Report of the X-33 Liquid Hydrogen Tank Test Investigation Team, George C. Marshall Space Flight Center, Huntsville, NASA Report, 2000, May.

4. Morino, Y., et al., Feasibility Study of CFRP Material Application to the Cryogenic Propellent Tank of Reusable Launch Vehicles in Japan International SAMPE Symposium, 1999, Vol. 2, p.1127-1130.

5. Callaghan, M.T., Use of resin composites for cryogenic tankage, Cryogenics, 1991, 31: p. 282287.

6. Pannkoke, K. and H.J. Wagner, Fatigue properties of unidirectional carbon fibre composites at cryogenic temperatures, Cryogenics, 1991, 31: p. 248-251.

7. Ahlborn, K., Durability of carbon fibre reinforced plastics with thermoplastic matrices under cyclic mechanical and cyclic thermal loads at cryogenic temperatures, Cryogenics, 1991, 31: p. 257-260.

8. Ahlborn, K., Cryogenic mechanical response of carbon fibre reinforced plastics with thermoplastic matrices to quasi-static loads, Cryogenics, 1991, 31: p. 252-256.

9. Perepechko, I., Low-Temperaturre Properties of Polymers. 1977, Moscow: Mir Publishers.

10. Schutz, J.B., Properties of composite materials for cryogenic applications, Cryogenics, 1998, 38(1): p. 3-12.

11. Schoeppner, G.A., R. Kim, and S.L. Donaldson, Steady State Cracking of PMCs at Cryogenic Temperatures in AIAA 42nd SDM Conference, April 16, 2001, Seattle, WA, AIAA-2001-1216.

12. Shimoda, T., et al., Study of CFRP Application to the Cryogenic Propellent Tank of Reusable Launch Vehicle in 42nd AIAA SDM Conference, April 16, 2001, Seattle, WA, AIAA-2001-1598. 
13. Kessler, S.S., T. Matuszeski, and H.L. McManus, Cryocycling and Mechanical Testing of CFRP for the X-33 Liquid H2 Fuel Tank Structure in 16th Annual Technical Conference, American Society for Composites, September 10, 2001, Blacksburg, ASC2001-093.
14. Jones, R.M., Mechanics of Composite Materials. 1975, Washington, D.C.: Scripta Book Company.

Table 1. Test matrix illustrating the residual test temperature and aging condition for each type of laminate

\begin{tabular}{|c|c|c|c|c|}
\hline \multirow[b]{2}{*}{$\begin{array}{c}\text { Test Temperature } \\
\left({ }^{\circ} \mathrm{C}\right)\end{array}$} & \multicolumn{4}{|c|}{ Mechanical load condition during isothermal aging } \\
\hline & No load & $\begin{array}{l}\text { Static load } \\
(3000 \mu \varepsilon)\end{array}$ & $\begin{array}{l}\text { Static load } \\
(4000 \mu \varepsilon)\end{array}$ & Cyclic load \\
\hline 23 & $\begin{array}{c}{[0]_{12},[90]_{12}} \\
{[ \pm 45]_{3 \mathrm{~s}},[ \pm 25]_{3 \mathrm{~s}}} \\
{\left[45 / 90_{3} /-45 / \overline{0}_{3}\right]_{\mathrm{s}}}\end{array}$ & $\begin{array}{c}{[ \pm 45]_{12}} \\
{[0]_{12}}\end{array}$ & $\begin{array}{c}{[ \pm 25]_{3 \mathrm{~s}}} \\
{\left[45 / 90_{3} /-45 / \overline{0}_{3}\right]_{\mathrm{s}}}\end{array}$ & 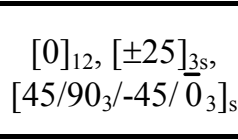 \\
\hline-196 & $\begin{array}{c}{[0]_{12},[90]_{12}} \\
{[ \pm 45]_{3 \mathrm{~s}},[ \pm 25]_{3 \mathrm{~s}}} \\
{\left[45 / 90_{3} /-45 / \overline{0}_{3}\right]_{\mathrm{s}}}\end{array}$ & $\begin{array}{c}{[ \pm 45]_{12},} \\
{[0]_{12}}\end{array}$ & $\begin{array}{c}{[ \pm 25]_{3 \mathrm{~s}}} \\
{\left[45 / 90_{3} /-45 / \overline{0}_{3}\right]_{\mathrm{s}}}\end{array}$ & $\begin{array}{c}{[0]_{12},[ \pm 25]_{3 \mathrm{~s}}} \\
{\left[45 / 90_{3} /-45 / \overline{0}_{3}\right]_{\mathrm{s}}}\end{array}$ \\
\hline-269 & $\begin{array}{c}{[0]_{12},[90]_{12}} \\
{[ \pm 45]_{3 \mathrm{~s}},[ \pm 25]_{3 \mathrm{~s}},} \\
{\left[45 / 90_{3} /-45 / \overline{0}_{3}\right]_{\mathrm{s}}}\end{array}$ & $\begin{array}{c}{[ \pm 45]_{12},} \\
{[0]_{12}}\end{array}$ & $\begin{array}{c}{[ \pm 25]_{3 \mathrm{~s}}} \\
{\left[45 / 90_{3} /-45 / \overline{0}_{3}\right]_{\mathrm{s}}}\end{array}$ & $\begin{array}{c}{[0]_{12},[ \pm 25]_{3 \mathrm{~s}}} \\
{\left[45 / 90_{3} /-45 / \overline{0}_{3}\right]_{\mathrm{s}}}\end{array}$ \\
\hline
\end{tabular}

Table 2. Measured tensile elastic modulus values

\begin{tabular}{lllllll}
\hline $\begin{array}{l}\text { Specimen ply } \\
\text { Lay - up }\end{array}$ & $\begin{array}{l}\text { Temp } \\
{ }^{\circ} \mathrm{C}\end{array}$ & $\begin{array}{l}\text { Material } \\
\text { property }\end{array}$ & $\begin{array}{l}\text { Not aged } \\
\text { modulus } \\
(\mathrm{GPa}) \\
\pm \text { Std dev. }\end{array}$ & $\begin{array}{l}\text { Aged without load } \\
\text { modulus (GPa) } \\
\pm \text { Std dev. }\end{array}$ & $\begin{array}{l}\text { Aged with load } \\
\text { modulus (GPa) } \\
\pm \text { Std dev. }\end{array}$ & $\begin{array}{l}\text { Isothermal/ } \\
\text { mechanically } \\
\text { cycled (GPa) } \\
\pm \text { Std dev. }\end{array}$ \\
\hline$[0]_{12}$ & 24 & $\mathrm{E}_{1}$ & $157.6 \pm 9.3$ & $153.6 \pm 5.9$ & $147.2 \pm 2.6$ & $157.6 \pm 2.3$ \\
{$[0]_{12}$} & -196 & $\mathrm{E}_{1}$ & $151.6 \pm 2.2$ & $146.3 \pm 11.5$ & $149.2 \pm 1.9$ & $157.1 \pm 15.5$ \\
{$[0]_{12}$} & -269 & $\mathrm{E}_{1}$ & $145.1 \pm 7.4$ & $143.0 \pm 8.8$ & $158.6 \pm 20.8$ & $138.4 \pm 10.2$ \\
{$[ \pm 25]_{3 \mathrm{~S}}$} & 24 & $\mathrm{E}_{\mathrm{x}}$ & $71.9 \pm 1.0$ & $70.3 \pm 1.6$ & $59.8 \pm 2.6$ & $57.2 \pm 2.8$ \\
{$[ \pm 25]_{3 \mathrm{~S}}$} & -196 & $\mathrm{E}_{\mathrm{x}}$ & $75.7 \pm 0.8$ & $63.8 \pm 8.5$ & $71.5 \pm 3.0$ & $77.7 \pm 8.3$ \\
{$[ \pm 25]_{3 \mathrm{~S}}$} & -269 & $\mathrm{E}_{\mathrm{x}}$ & $73.1 \pm 3.7$ & 69.4 & $65.6 \pm 12.2$ & $81.76 \pm 6.6$ \\
{$\left[45 / 90_{3} /-45 / \overline{0}_{3}\right]_{\mathrm{S}}$} & 24 & $\mathrm{E}_{\mathrm{x}}$ & $50.7 \pm 1.0$ & $46.7 \pm 4.3$ & $51.0 \pm 1.1$ & $46.5 \pm 0.2$ \\
{$\left[45 / 90_{3} /-45 / \overline{0}_{3}\right]_{\mathrm{S}}$} & -196 & $\mathrm{E}_{\mathrm{x}}$ & $40.6 \pm 5.9$ & $48.0 \pm 1.8$ & $48.6 \pm 3.0$ & 46.0 \\
{$\left[45 / 90_{3} /-45 / \overline{0}_{3}\right]_{\mathrm{S}}$} & -269 & $\mathrm{E}_{\mathrm{x}}$ & $43.8 \pm 1.9$ & $44.3 \pm 3.9$ & $52.1 \pm 1.3$ & $52.0 \pm 9.4$ \\
{$[90]_{12}$} & 24 & $\mathrm{E}_{2}$ & $8.7 \pm 0.1$ & $8.6 \pm 0.1$ & $\mathrm{NA}$ & \\
{$[90]_{12}$} & -196 & $\mathrm{E}_{2}$ & $7.5 \pm 0.1$ & $9.5 \pm 2.0$ & $9.6 \pm 0.1$ & \\
{$[90]_{12}$} & -269 & $\mathrm{E}_{2}$ & $7.8 \pm 1.2$ & $7.1 \pm 0.8$ & $\mathrm{NA}$ & \\
{$[ \pm 45]_{3 \mathrm{~S}}$} & 24 & $\mathrm{G}_{12}$ & $4.6 \pm 0.4$ & $5.0 \pm 0.1$ & $5.8 \pm 0.2$ & \\
{$[ \pm 45]_{3 \mathrm{~S}}$} & -196 & $\mathrm{G}_{12}$ & $5.8 \pm 0.1$ & $6.2 \pm 0.1$ & $6.0 \pm 0.2$ & \\
{$[ \pm 45]_{3 \mathrm{~S}}$} & -269 & $\mathrm{G}_{12}$ & $6.2 \pm 0.2$ & $5.5 \pm 0.9$ & $6.1 \pm 0.3$ & \\
$(\mathrm{NA}=$ not available $)$ & & & & &
\end{tabular}


Table 3. Measured compressive elastic modulus values

\begin{tabular}{lccccc}
\hline \hline $\begin{array}{c}\text { Specimen ply } \\
\text { lay - up }\end{array}$ & $\begin{array}{c}\text { Temp } \\
{ }^{\circ} \mathrm{C}\end{array}$ & $\begin{array}{c}\text { Material } \\
\text { property }\end{array}$ & $\begin{array}{c}\text { Not aged } \\
\text { modulus (GPa) } \\
\pm \text { Std dev. }\end{array}$ & $\begin{array}{c}\text { Aged without load } \\
\text { modulus (GPa) } \\
\pm \text { Std dev. }\end{array}$ & $\begin{array}{c}\text { Aged with load } \\
\text { modulus (GPa) } \\
\pm \text { Std dev. }\end{array}$ \\
\hline$[0]_{12}$ & 24 & $\mathrm{E}_{1}$ & $135.2 \pm 1.1$ & $139.0 \pm 3$ & $129.9 \pm 4.8$ \\
{$[0]_{12}$} & -196 & $\mathrm{E}_{1}$ & $142.0 \pm 15.0$ & $154.0 \pm 5.9$ & $147.9 \pm 5.5$ \\
{$[0]_{12}$} & -269 & $\mathrm{E}_{1}$ & $146.9 \pm 11.1$ & $143.1 \pm 6.0$ & $139.9 \pm 11.4$ \\
{$[ \pm 25]_{3 \mathrm{~S}}$} & 24 & $\mathrm{E}_{\mathrm{x}}$ & $63.2 \pm 5.7$ & $60.0 \pm 4.1$ & $62.8 \pm 3.1$ \\
{$[ \pm 25]_{3 \mathrm{~S}}$} & -196 & $\mathrm{E}_{\mathrm{x}}$ & $64.1 \pm 7.5$ & $72.1 \pm 8.0$ & $72.6 \pm 2.5$ \\
{$[ \pm 25]_{3 \mathrm{~S}}$} & -269 & $\mathrm{E}_{\mathrm{x}}$ & $77.5 \pm 17.5$ & $77.3 \pm 9.4$ & $69.5 \pm 1.7$ \\
{$\left[45 / 90_{3} /-45 / \overline{0}_{3}\right]_{\mathrm{S}}$} & 24 & $\mathrm{E}_{\mathrm{x}}$ & $44.3 \pm 5.1$ & $46.3 \pm 0.9$ & $40.7 \pm 7.6$ \\
{$\left[45 / 90_{3} /-45 / \overline{0}_{3}\right]_{\mathrm{S}}$} & -196 & $\mathrm{E}_{\mathrm{x}}$ & $60.6 \pm 7.3$ & $50.8 \pm 4.8$ & $52.2 \pm 7.0$ \\
{$\left[45 / 90_{3} /-45 / \overline{0}_{3}\right]_{\mathrm{S}}$} & -269 & $\mathrm{E}_{\mathrm{x}}$ & $51.2 \pm 4.2$ & $47.6 \pm 1.1$ & $53.7 \pm 5.0$ \\
{$[90]_{12}$} & & & & & \\
{$[90]_{12}$} & 24 & $\mathrm{E}_{2}$ & $11.6 \pm 1.7$ & $12.1 \pm 0.5$ & $\mathrm{NA}$ \\
{$[90]_{12}$} & -196 & $\mathrm{E}_{2}$ & $11.9 \pm 1.1$ & $11.1 \pm 0.5$ & $\mathrm{NA}$ \\
{$[ \pm 45]_{3 \mathrm{~S}}$} & -269 & $\mathrm{E}_{2}$ & $12.8 \pm 1.1$ & $12.2 \pm 01.6$ & $\mathrm{NA}$ \\
{$[ \pm 45]_{3 \mathrm{~S}}$} & 24 & $\mathrm{G}_{12}$ & $4.8 \pm 2.5$ & $5.3 \pm 0.5$ & $4.3 \pm 0.1$ \\
{$[ \pm 45]_{3 \mathrm{~S}}$} & -196 & $\mathrm{G}_{12}$ & $6.7 \pm 0.8$ & $5.4 \pm 0.5$ & $6.0 \pm 1.2$ \\
\hline \hline
\end{tabular}

Table 4. Measured tensile strength values

\begin{tabular}{ccllll}
\hline \hline $\begin{array}{c}\text { Specimen ply } \\
\text { lay- up }\end{array}$ & $\begin{array}{c}\text { Temp } \\
{ }^{\circ} \mathrm{C}\end{array}$ & $\begin{array}{c}\text { Not aged } \\
\text { strength (MPa) } \\
\pm \text { Std dev. }\end{array}$ & $\begin{array}{c}\text { Aged without load } \\
\text { strength (MPa) } \\
\pm \text { Std dev. }\end{array}$ & $\begin{array}{c}\text { Aged with load } \\
\text { strength (MPa) } \\
\pm \text { Std dev. }\end{array}$ & $\begin{array}{c}\text { Isothermal/ } \\
\text { mechanically cycled } \\
(\mathrm{MPa}) \pm \text { Std dev. }\end{array}$ \\
\hline$[0]_{12}$ & 24 & $1940 \pm 276$ & $1865 \pm 44$ & $1848 \pm 49$ & $1105 \pm 374$ \\
{$[0]_{12}$} & -196 & $1287 \pm 207$ & $1568 \pm 59$ & $1536 \pm 126$ & $1549 \pm 51$ \\
{$[0]_{12}$} & -269 & $1495 \pm 326$ & $1451 \pm 243$ & $1771 \pm 186$ & $1620 \pm 302$ \\
{$[ \pm 25]_{3 \mathrm{~S}}$} & 24 & $1132 \pm 77$ & $1266 \pm 58$ & $955 \pm 84$ & $857 \pm 39$ \\
{$[ \pm 25]_{3 \mathrm{~S}}$} & -196 & $912 \pm 49$ & $902 \pm 208$ & $1120 \pm 51$ & $945 \pm 127$ \\
{$[ \pm 25]_{3 \mathrm{~S}}$} & -269 & $1131 \pm 15$ & 1114 & $1024 \pm 209$ & $1024 \pm 22$ \\
{$\left[45 / 90_{3} /-45 / \overline{0}_{3}\right]_{\mathrm{S}}$} & 24 & $711 \pm 14$ & $700 \pm 67$ & & $679 \pm 5$ \\
{$\left[45 / 90_{3} /-45 / \overline{0}_{3}\right]_{\mathrm{S}}$} & -196 & $585 \pm 119$ & $748 \pm 57$ & $843 \pm 38$ & 717 \\
{$\left[45 / 90_{3} /-45 / \overline{0}_{3}\right]_{\mathrm{S}}$} & -269 & $656 \pm 48$ & $732 \pm 64$ & $806 \pm 2$ & $688 \pm 48$ \\
{$[90]_{12}$} & 24 & $47 \pm 2$ & $47 \pm 3$ & $\mathrm{NA}$ & \\
{$[90]_{12}$} & -196 & $21 \pm 4$ & $58 \pm 30$ & $63 \pm 5$ & \\
{$[90]_{12}$} & -269 & $17 \pm 4$ & $11 \pm 5$ & $\mathrm{NA}$ & \\
{$[ \pm 45]_{3 \mathrm{~S}}$} & 24 & $163 \pm 2$ & $165 \pm 1$ & $182 \pm 4$ & \\
{$[ \pm 45]_{35}$} & -196 & $242 \pm 4$ & $249 \pm 3$ & $245 \pm 8$ & \\
{$[ \pm 45]_{35}$} & -269 & $256 \pm 8$ & $257 \pm 12$ & $257 \pm 5$ & \\
\hline \hline
\end{tabular}

(NA $=$ not available) Note: Strength of $[ \pm 45]_{3 \mathrm{~S}}$ was defined as the initial point of deviation from the tangent of the nearly horizontal slope of the stress strain curve. 
Table 5. Measured compressive strength values

\begin{tabular}{ccccc}
\hline $\begin{array}{c}\text { Specimen ply } \\
\text { lay- up }\end{array}$ & $\begin{array}{c}\text { Temp } \\
{ }^{\circ} \mathrm{C}\end{array}$ & $\begin{array}{c}\text { Not aged } \\
\text { strength (MPa) } \\
\pm \text { Std dev. }\end{array}$ & $\begin{array}{c}\text { Aged without load } \\
\text { strength (MPa) } \\
\pm \text { Std dev. }\end{array}$ & $\begin{array}{c}\text { Aged with load } \\
\text { strength (MPa) } \\
\pm \text { Std dev. }\end{array}$ \\
\hline$[0]_{12}$ & 24 & $857.5 \pm 52.5$ & $856.2 \pm 102.4$ & $817.4 \pm 74.2$ \\
{$[0]_{12}$} & -196 & $1124.8 \pm 127.6$ & $1167.2 \pm 60.9$ & $1115.2 \pm 66.2$ \\
{$[0]_{12}$} & -269 & $1193.5 \pm 100.8$ & $1234.7 \pm 44.6$ & $1156.1 \pm 61.0$ \\
{$[ \pm 25]_{3 \mathrm{~S}}$} & 24 & $502.9 \pm 65.7$ & $467.7 \pm 37.2$ & $524.8 \pm 43.4$ \\
{$[ \pm 25]_{3 \mathrm{~S}}$} & -196 & $604.2 \pm 9.6$ & $709.5 \pm 0.3$ & $685.6 \pm 87.2$ \\
{$[ \pm 25]_{3 \mathrm{~S}}$} & -269 & $714.8 \pm 132.7$ & $749.4 \pm 27.2$ & $571.2 \pm 61.5$ \\
{$\left[45 / 90_{3} /-45 / \overline{0}_{3}\right]_{\mathrm{S}}$} & 24 & $473.3 \pm 121.8$ & $432.6 \pm 10.2$ & $530.6 \pm 107.5$ \\
{$\left[45 / 90_{3} /-45 / \overline{0}_{3}\right]_{\mathrm{S}}$} & -196 & $375.7 \pm 130.1$ & $554.3 \pm 29.8$ & $709.5 \pm 89.2$ \\
{$\left[45 / 90_{3} /-45 / \overline{0}_{3}\right]_{\mathrm{S}}$} & -269 & $572.2 \pm 28.6$ & $619.1 \pm 11.9$ & $723.0 \pm 113.4$ \\
{$[90]_{12}$} & 24 & $220.0 \pm 10.0$ & $280.0 \pm 11.5$ & NA \\
{$[90]_{12}$} & -196 & $293.7 \pm 16.1$ & $273.7 \pm 52.7$ & NA \\
{$[90]_{12}$} & -269 & $367.6 \pm 35.1$ & $301.9 \pm 21.8$ & NA \\
{$[ \pm 45]_{3 \mathrm{~S}}$} & 24 & $426.7 \pm 27.7$ & $398.3 \pm 26.4$ & $364.8 \pm 12.2$ \\
{$[ \pm 45]_{3 \mathrm{~S}}$} & -196 & $536.8 \pm 73.3$ & $511.0 \pm 57.1$ & $530.5 \pm 21.4$ \\
{$[ \pm 45]_{3 \mathrm{~S}}$} & -269 & $578.1 \pm 13.8$ & $569.5 \pm 10.38$ & $454.6 \pm 98.0$ \\
\hline \hline
\end{tabular}

$(\mathrm{NA}=$ not available $)$

Table 6. Coefficient of thermal expansion for not aged IM7/PETI-5 material system

\begin{tabular}{ccc}
\hline & \multicolumn{2}{c}{$\mu \mathrm{mm} / \mathrm{mm}-{ }^{\circ} \mathrm{C}$} \\
\cline { 2 - 3 } Temp $\left({ }^{\circ} \mathrm{C}\right)$ & {$[0]_{12}$} & {$[90]_{12}$} \\
\cline { 2 - 3 } 24 & -1.30 & 19.45 \\
-196 & -1.49 & 20.05 \\
-273 & -2.77 & 18.46 \\
\hline \hline
\end{tabular}



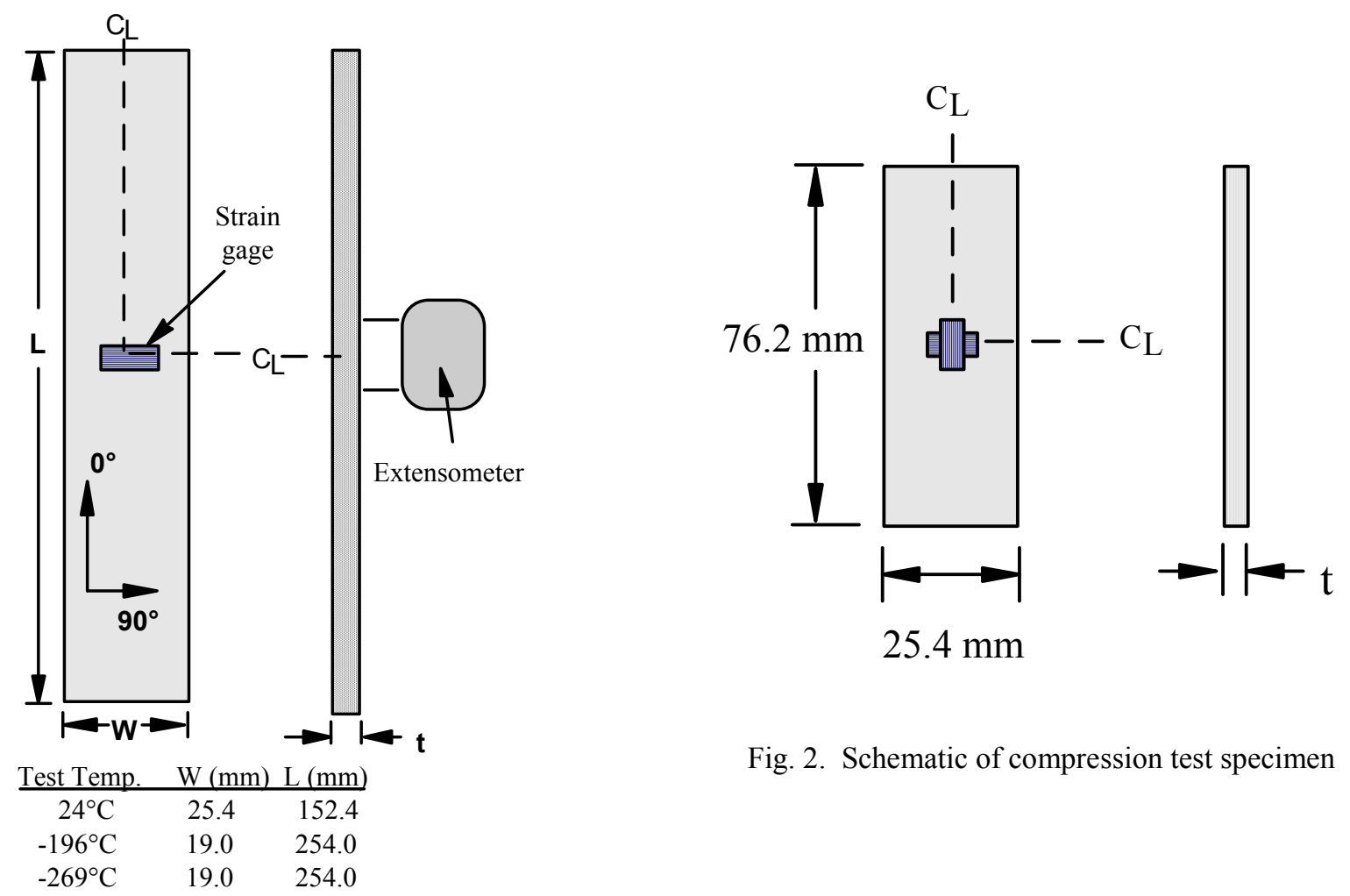

Fig. 2. Schematic of compression test specimen

Fig. 1. Schematic of tension test specimen.

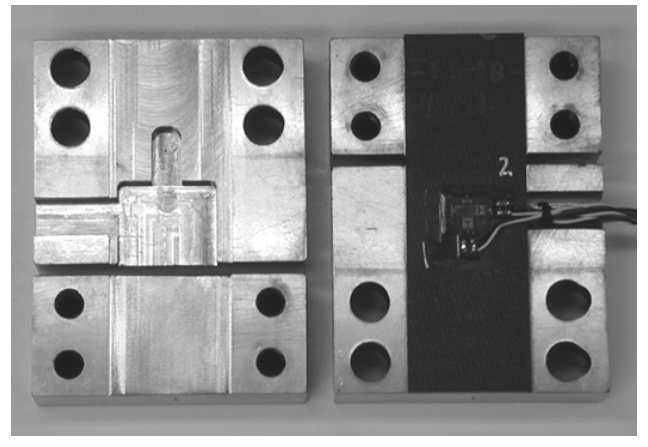

3a) Open fixture and specimen 3b) Closed fixture

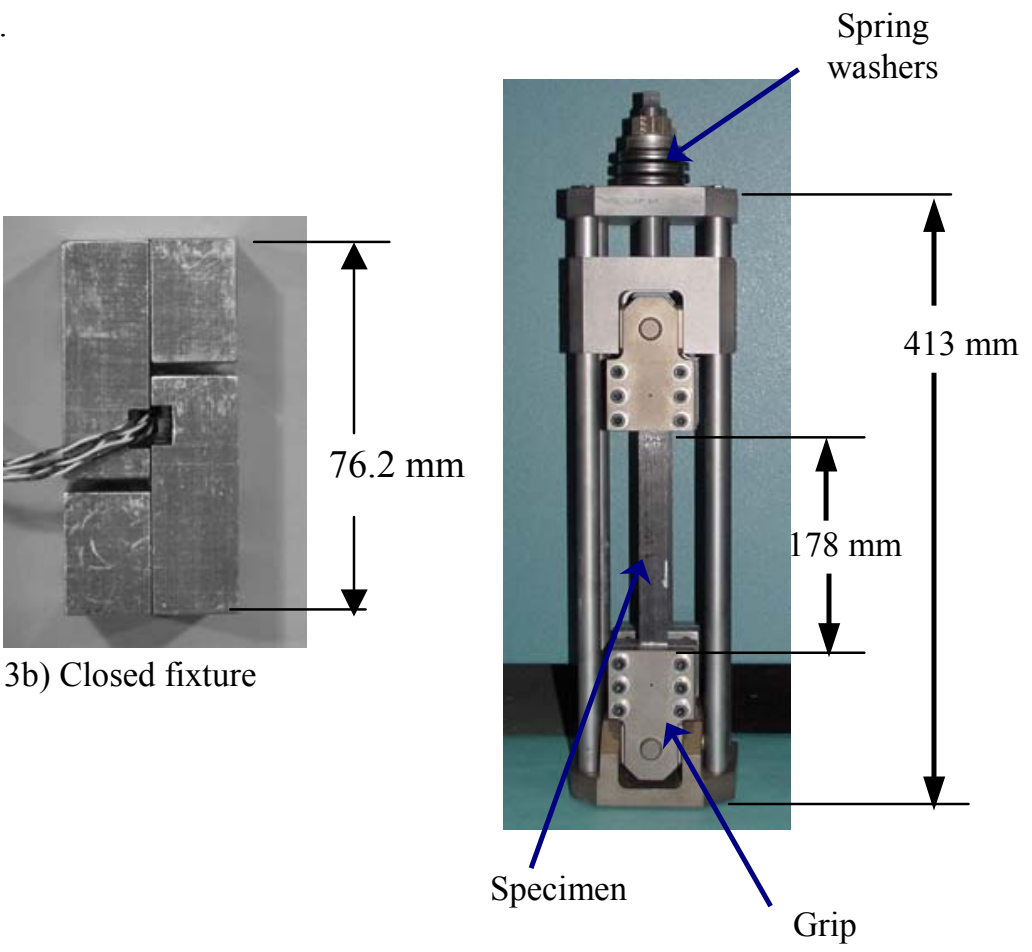

Fig. 3. Compression test fixture.

Figure 4. Constant strain aging fixture. 


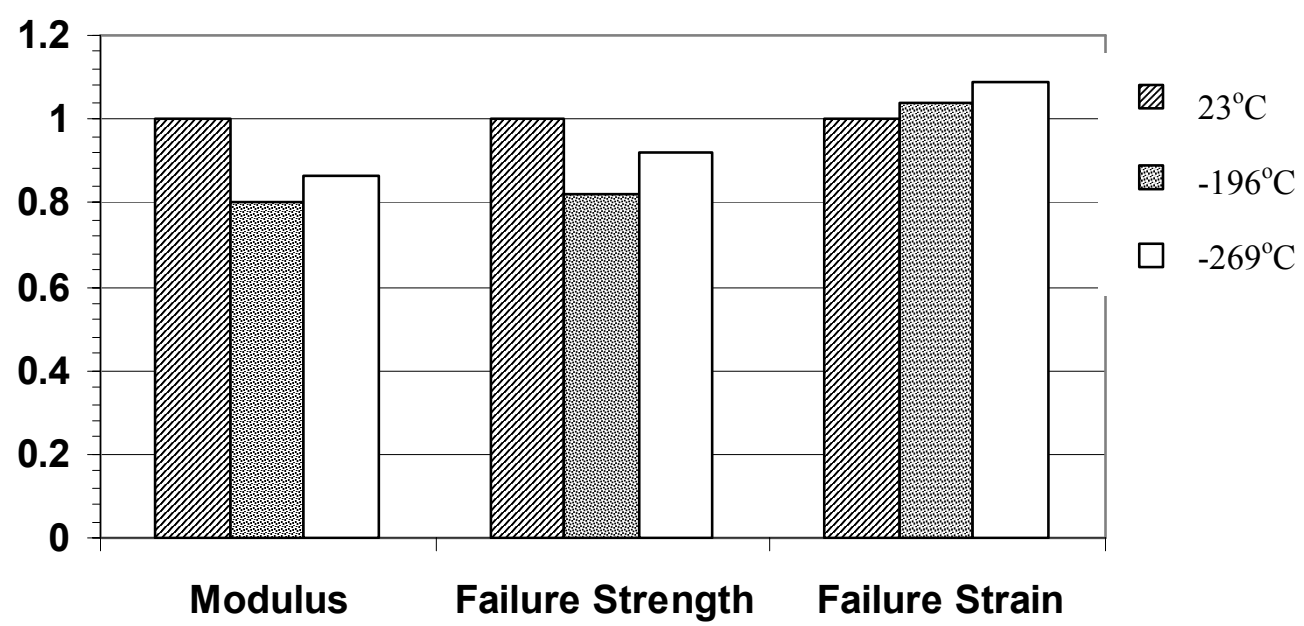

Fig. 5. Effect of test temperature on the not-aged properties of $\left[45 / 90_{3} /-45 /{ }_{3}\right]_{\mathrm{S}}$ laminate. Each set of values is normalized against their individual, $23^{\circ} \mathrm{C}$ condition.

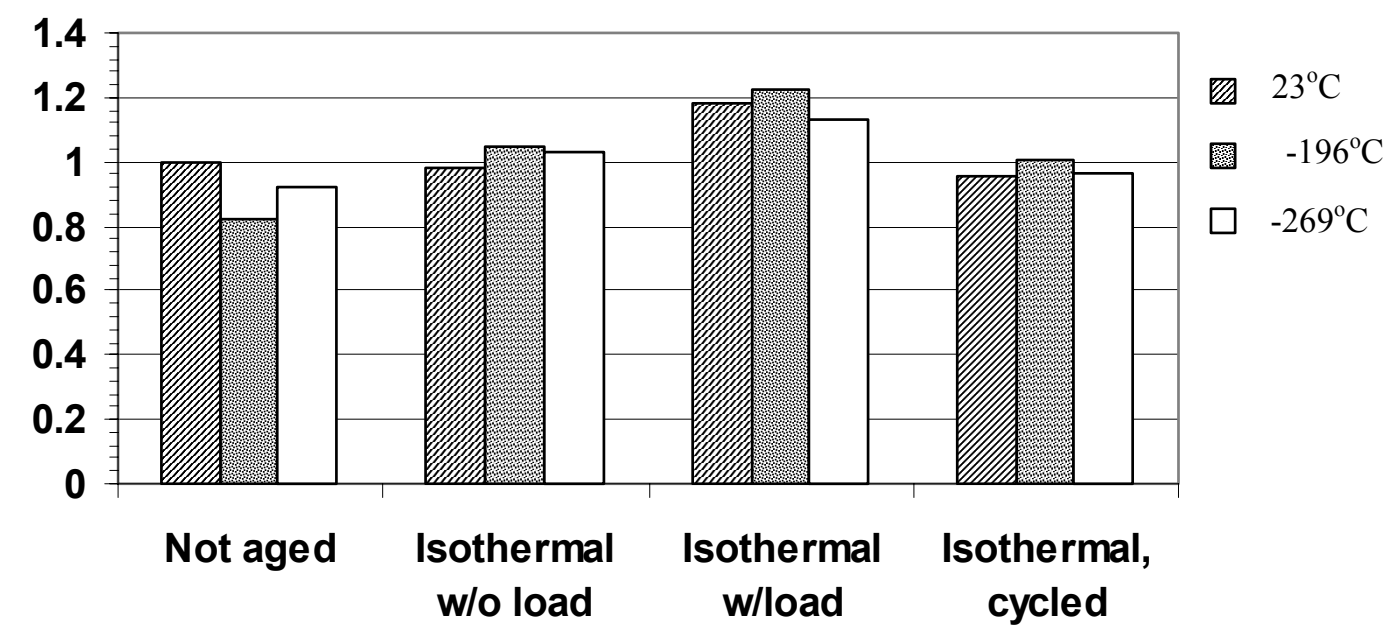

Fig. 6. Effect of aging condition on the residual strength of $\left[45 / 90_{3} /-45 / \overline{0}_{3}\right]_{\mathrm{S}}$ laminate. Each set of values is normalized against the $23^{\circ} \mathrm{C}$, not-aged condition. 


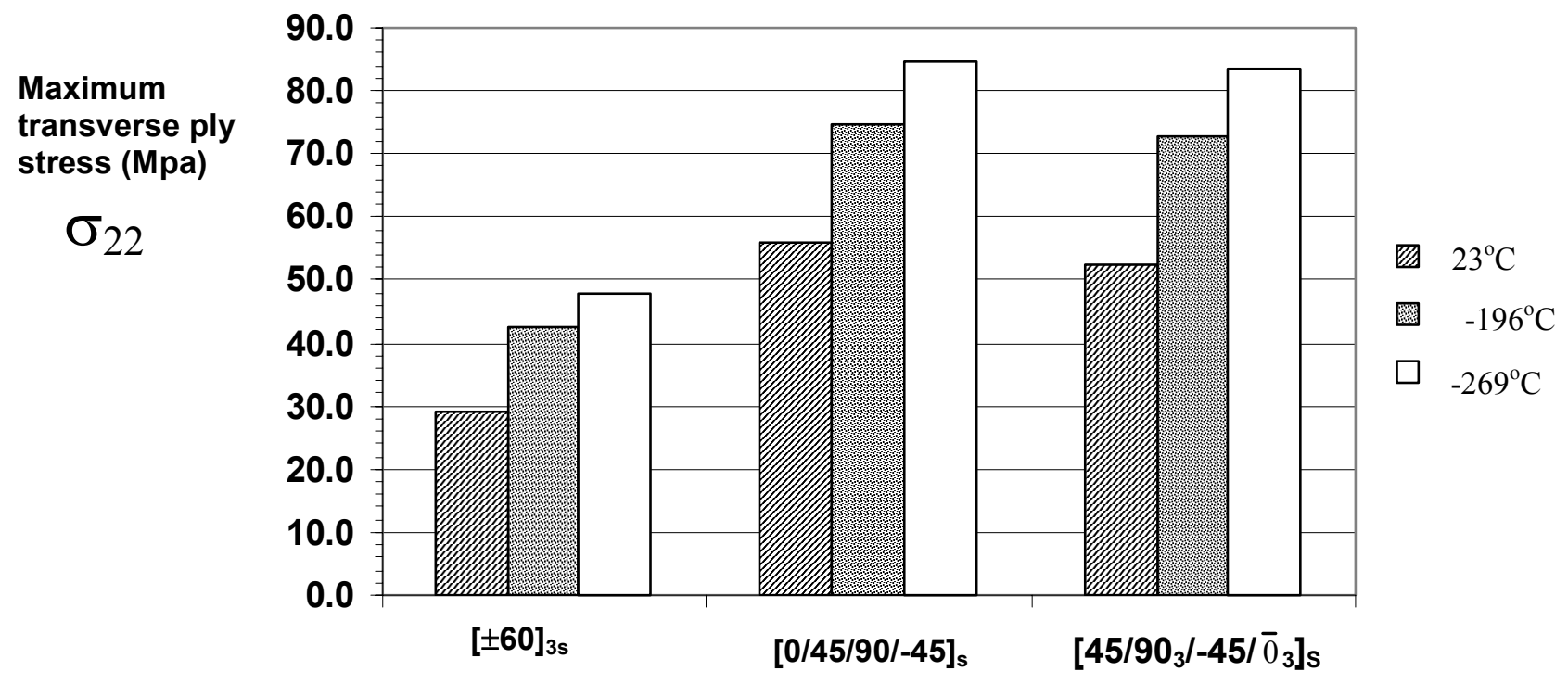

Fig. 7. Predicted effects of temperature on maximum transverse ply stress for thermal loading only.

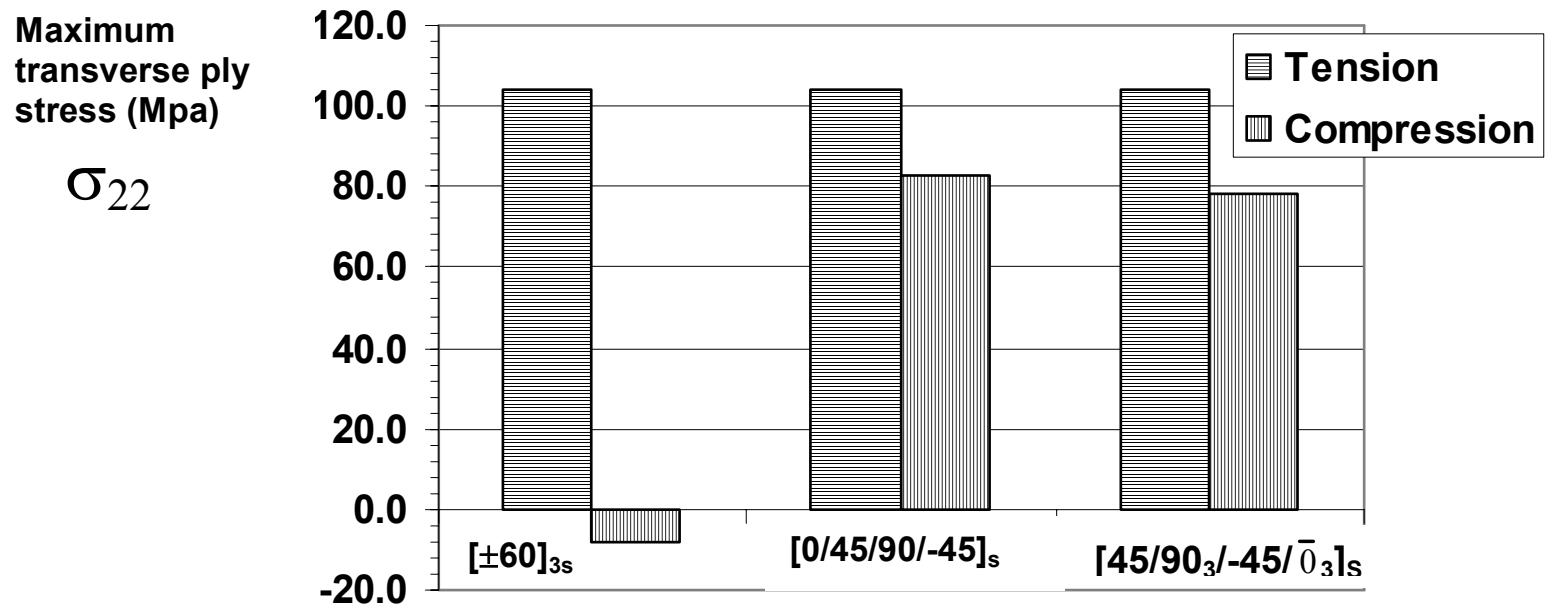

Fig. 8. Predicted effects of temperature on maximum transverse ply stress for combined mechanical $( \pm .4 \%)$ and thermal loading $\left(-269^{\circ} \mathrm{C}\right)$.

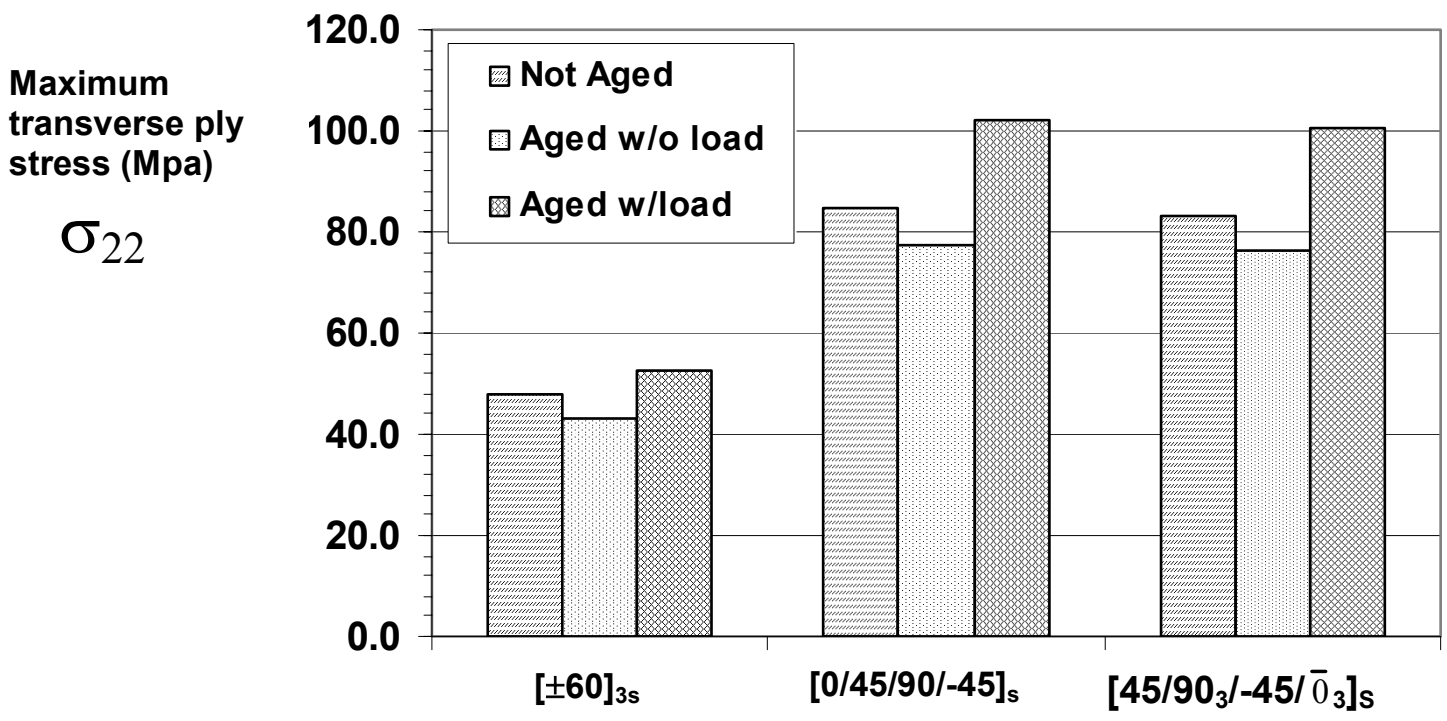

Fig. 9. Predicted effects of aging on maximum transverse ply stress for thermal loading only $\left(-269^{\circ} \mathrm{C}\right)$. 